MS. KATRINA A LAMBERT (Orcid ID : 0000-0002-9079-999X)

DR. CAROLINE LODGE (Orcid ID : 0000-0002-2342-3888)

DR. ADRIAN LOWE (Orcid ID : 0000-0002-4691-8162)

DR. BIRCAN ERBAS (Orcid ID : 0000-0001-9597-418X)

6

7

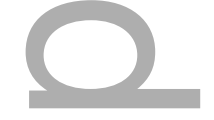

Article type : Original Article: Epidemiology and Genetics

\title{
Pollen exposure at birth and adolescent lung function, and modification by residential
} greenness.

Katrina A Lambert $(\mathrm{BSc})^{1}$, Caroline Lodge $(\mathrm{PhD})^{2}$, Adrian J Lowe $(\mathrm{PhD})^{2}$, Luke A

Prendergast $(\mathrm{PhD})^{3}$, Paul S Thomas $(\mathrm{MD})^{4}$, Catherine M Bennett $(\mathrm{PhD})^{5}$, Michael J

Abramson $(\mathrm{PhD})^{6}$, Shyamali C Dharmage $(\mathrm{PhD})^{2}$, Bircan Erbas $(\mathrm{PhD})^{1}$

1. Department of Public Health, School of Psychology and Public Health, La Trobe University, Melbourne, Australia

2. Allergy and Lung Health Unit, Centre for Epidemiology and Biostatistics, School of Population and Global Health, The University of Melbourne, Australia

3. Department of Mathematics and Statistics, School of Engineering and Mathematical Sciences, La Trobe University, Melbourne, Australia

4. Prince of Wales' Hospital Clinical School and School of Medical Sciences, Faculty of Medicine, University of New South Wales, Sydney, Australia

5. Centre for Population Health Research, Deakin University, Melbourne, Australia

6. School of Public Health \& Preventive Medicine, Monash University, Melbourne, Australia

\section{Corresponding author}

Shyamali C Dharmage

Allergy and Lung Health Unit, Centre for Epidemiology and Biostatistics,

School of Population and Global Health,

This is the author manuscript accepted for publication and has undergone full peer review but has not been through the copyediting, typesetting, pagination and proofreading process, which may lead to differences between this version and the Version of Record. Please cite this article as doi: $10.1111 /$ ALL.13803

This article is protected by copyright. All rights reserved 
The University of Melbourne,

Level 3, 207 Bouverie Street, Carlton, VIC 3053, Australia.

Email: s.dharmage@unimelb.edu.au

Phone: +61383440737

Fax: +61393495815

\section{Word count: 3189}

Short Title: Early life pollen on lung function

\section{Funding}

The first 6 years of the Melbourne Atopy Cohort Study was funded (study formula and staff) by Nestec Ltd, a subsidiary of Nestlé Australia. The 12-year follow-up was funded by a project grant from the Asthma Foundation of Victoria. The National Health and Medical Research Council of Australia funded the 18-year (APP454856) follow-up study. In 2013, the NHMRC-funded Centre for Air Quality and Health Research and Evaluation (CAR) provided a seeding grant for geocoding participants' addresses. All bodies that have funded aspects of the MACS have had no role in interpretation or publication of study findings.

\section{Statement of Contribution}

Shyamali C. Dharmage, Adrian J. Lowe, Michael J. Abramson, Paul S Thomas, Catherine M

3 Bennett and Caroline J. Lodge designed, obtained funding and conducted the Melbourne

4 Atopic Cohort Study. Katrina A Lambert, Bircan Erbas and Luke A Prendergast led the 5 analysis of data. All authors contributed to interpreting of the data, drafting the manuscript, to 6 the intellectual content and revising of the final draft of the manuscript. The final version of 7 the manuscript was approved by all the authors.
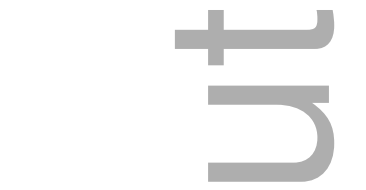

\section{Conflict of Interest}

Katrina Lambert is funded by a La Trobe University PhD Postgraduate Scholarship and a 3 Research Funding Area: Building Healthy Communities top-up scholarship. Caroline Lodge, 4 Adrian J Lowe and Shyamali C Dharmage are supported by NHMRC fellowships. Michael 65 Abramson holds investigator initiated research grants from Pfizer and Boehringer-Ingelheim 
66 for unrelated research. He has also received assistance with conference attendance from 67 Sanofi. All authors declare no conflict of interest.

68

69

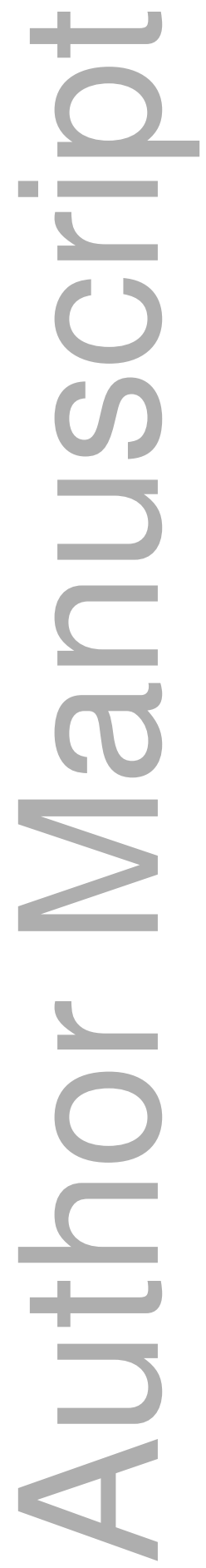




\section{ABSTRACT}

Background: Exposure to high levels of pollen in infancy is a risk factor for allergic respiratory diseases in later childhood, but effects on lung function are not fully understood. We aim to examine associations between grass pollen exposure in the first months of life and lung function at 12 and 18 years, and explore potential modification. Methods: Using the Melbourne Atopy Cohort Study, a birth cohort of children with a family history of allergic diseases, we modelled the association between cumulative grass pollen exposure up to 3 months after birth, on $\mathrm{FEV}_{1}, \mathrm{FVC}$ and $\mathrm{FEV}_{1} / \mathrm{FVC}$ ratio at 12 and 18 years. We also assessed modifying effects of residential greenness levels (derived from satellite imagery), asthma and early life sensitization to rye grass.

Results: Grass pollen exposure in the first seven days was associated with a reduction in $\mathrm{FEV}_{1}(-15.5 \mathrm{~mL} ; 95 \% \mathrm{CI}$ : -27.6, -3.3 per doubling of pollen count) and FVC (-20.8mL; -35.4, $-6.1)$ at 12 years, but not at 18 years. Increase in cumulative grass pollen exposure up to 3 months were negatively associated with FVC at 12 and 18. Higher residential greenness increased the reduction in FVC associated with exposure pollen in the first three months of life

Conclusion: Early exposure to grass pollen was associated with decreased lung function in children and adolescents. Targeted interventions for pollen avoidance strategies that take into account local topography could be implemented alongside other clinical interventions such as immunotherapy.

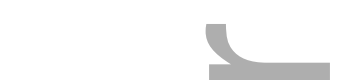

Keywords: aeroallergen; greenness; pollen; spirometry

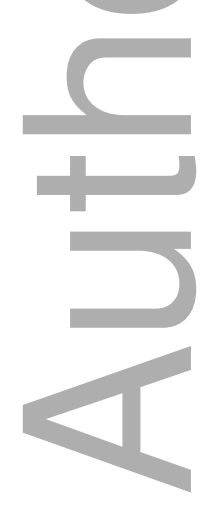




\section{INTRODUCTION}

Asthma and chronic obstructive pulmonary disease (COPD) are urgent public health problems with high rates of morbidity and mortality ${ }^{1}$. Reduced lung function at age 7 has been shown to predict COPD and asthma-COPD overlap syndrome at age $45^{2}$. Environmental factors are important in modifying the development of lung function, but to date most studies have only looked at air pollutants ${ }^{3,4}$. The potential effect of pollen exposure on lung function has received limited attention. Previous work has mainly assessed the association between pollen exposure and lung function in short term studies over a single pollen season 5-7. These studies found a correlation between increasing pollen levels and increased levels of fractional expired nitric oxide (FeNO), but no association with forced expired volume in one second $\left(\mathrm{FEV}_{1}\right)$. A more recent cross-sectional study of a Swedish cohort ${ }^{8}$ found exposure to grass pollen during the preceding day to be associated with a reduction in $\mathrm{FEV}_{1}$ at age 8. They found the negative effect of grass pollen on lung function was stronger in children sensitized to pollen allergens.

Studies including our own have shown that exposure to grass pollen in the first 3 months of life was associated with allergy and asthma ${ }^{9,10}$. We have also shown that exposure to grass pollen during the first 3 months of life was associated with hay fever, and exposure by 6 months with asthma later in childhood ${ }^{9}$. Harvey and colleagues reported increased odds of wheeze at age 2 years in infants exposed to cypress, pine and alder pollen in the first 3 months of life. This birth cohort recruited mothers from a Mexican background in an agricultural region of California ${ }^{10}$. However, no study has yet examined the effect on lung function of grass pollen exposure at birth or in the first 3 months of life in children or adolescents.

Understanding the role of greenness surrounding a participants' home may also be important in pollen exposure pathways. The Normalised Difference Vegetation Index (NDVI) provides a broad measure of vegetation around the home that is of increasing interest ${ }^{11,12}$. Assessing the modifying effects of residential greenness may be important in better understanding the role of grass pollen exposure in temperate regions.

Melbourne experiences high ambient levels of rye grass pollen in spring, making it a useful setting to assess the risk of grass pollen exposure in the first months of life on subsequent 
130 lung function in adolescents. Using the Melbourne Atopy Cohort Study (MACS), an

131 established birth cohort of children with a family history of allergic disease, we examined the

132 associations between persistent exposure to cumulative grass pollen in the first seven days,

133 and again at three months of life, on subsequent lung function at 12 and 18 years. Secondary

134 aims were to assess whether these associations were modified by local residential greenness

135 and whether asthma in childhood or sensitization to rye grass mediated these associations.

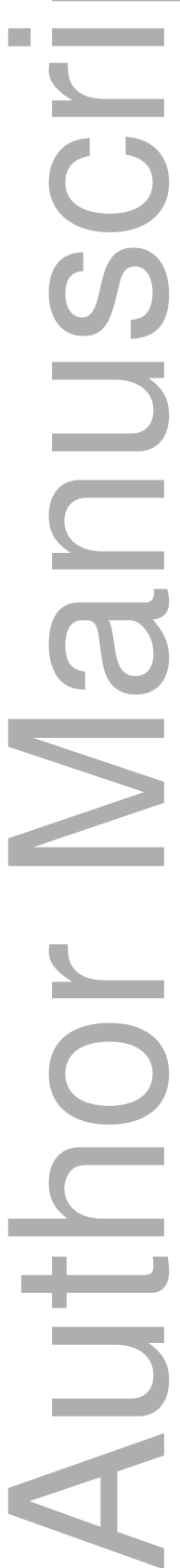


METHODS

137

138 Study design and population

139 The Melbourne Atopy Cohort Study (MACS) commenced as a randomized controlled trial

140 (RCT) of 620 infants, with at least one first-degree relative with a history of allergic disease

141 (self-reported asthma, eczema, hay fever or severe food allergy). Infants were recruited

142 between 1990 and 1994 from Melbourne, Australia ${ }^{13}$. The initial RCT investigated the effect

143 of three types of formula (cows' milk, soya or partially hydrolyzed whey formula) on risk of

144 allergic disease ${ }^{14}$. It has since been analyzed as an observational birth cohort study for

145 nonrandomized exposures. Clinical assessments of MACS participants were performed at

146 ages 12 and 18 years. Ethics approval was granted by the Mercy Maternity and Royal

147 Children's Hospitals and, to conduct of this analysis, from La Trobe University Ethics

148 Committees. Written informed consent was obtained from all mothers, and from all

149 participants at the 18 -year follow-up.

150

Data collection and measurements

152

153

Demographic data

154 Baseline demographic details were obtained by questionnaire during pregnancy. Following

155 birth, standardized telephone questionnaires were administered by a research nurse trained in

156 allergy. These questionnaires were administered every 4 weeks from birth to 64 weeks, at 78

157 weeks and at 2 years, documenting any episodes of illness since the previous interview. An

158 annual follow up was then conducted until the children were 7 years old. Further data

159 collection occurred between 2002 and 2006 (mean age 12 years) and 2009 and 2013 (age 18

160 years). The International Study of Asthma and Allergies in Childhood (ISAAC)

161 questionnaire was administered at 12 and 18 years. Anthropometric measurements were

162 obtained at 12 and 18 years (height to nearest $0.1 \mathrm{~cm}$ and weight to the nearest $0.1 \mathrm{~kg}$ ).

\section{Pollen Exposure}

165 Daily, 24-hour average pollen concentrations $\left(\right.$ grains $\left./ \mathrm{m}^{3}\right)$, grass pollen counts collected from

166 a single Burkard volumetric trap, located on the roof of the University of Melbourne, were

167 collected from the 1st of October 1991 until the 30th of December 1993.

Residential greenness

This article is protected by copyright. All rights reserved 
170 Local residential greenness was calculated by the Normalized Difference Vegetation Index

171 (NDVI) derived from the publically available Landsat 5 Thematic Mapper Surface

172 Reflectance images (https://earthexplorer.usgs.gov/), with one image taken every 16-days at a

17330 by 30 -meter pixel resolution. Buffers of 100,500 and 1000 around the residential home

174 address at birth were calculated using QGIS 2.18.15 (Open Source Geospatial Foundation).

175 Each participant was matched to a suitable cloud-free $(<10 \%$ cloud cover) image as close to

176 the date of birth as possible, with $77 \%$ of images matched within one month of birth. NDVIs

177 were computed by linear interpolation for participants without a suitable cloud-free image in

178 this time period, taking the mean of the NDVIs for the closest day/month one year prior and

179 one year after their date of birth.

180

Lung function

182 Pre-bronchodilator spirometry was measured at both 12 and 18 years, while post

183 bronchodilator spirometry was only performed during the 18 year follow up. Spirometry was

184 performed according to then current American Thoracic Society (ATS) (1994) or

185 ATS/European Respiratory Society (2005) guidelines ${ }^{15}$. Participants were advised to abstain

186 from short-acting bronchodilators for 4 hours and long-acting bronchodilators for 12 hours

187 before spirometry. The Global Lung Initiative reference values were used to calculate z-

188 scores for sensitivity analysis.

190 Other variables

191 Childhood diagnosis of asthma: Report of doctor diagnosed asthma in the previous 12 months

192 collected from parents during the telephone interviews conducted when children were aged 6

193 or 7 years. Upper respiratory tract infection (URTI) before 5 weeks: report of an URTI

194 collected from parents' report during telephone interviews conducted when children were 4 to

1955 weeks old. Early sensitization to rye: a positive reaction to skin prick testing (SPT) during

196 the 2 year follow up. A positive SPT was defined as a wheal of at least $3 \mathrm{~mm}$ diameter ${ }^{13}$.

197 Maternal education was assessed by questionnaire at baseline and used as a surrogate

198 measure of socio-economic status.

200 Statistical methods

201 We used linear regression to model the associations between grass pollen exposure and lung

202 function outcomes. Grass pollen exposure during early life was examined as the cumulative

203 count of grass pollen exposure over the first seven days ( 7 day) and three months (3 month) 
204 of life. The cumulative pollen data were analyzed after a log base 2 transformation with an offset of 1 was applied. An estimate of 1 can therefore be interpreted as an increase of $1 \mathrm{~mL}$ per doubling of the cumulative pollen count (from 10 to 20 grains $/ \mathrm{m}^{3}$ or from 25 to 50 grains $/ \mathrm{m}^{3}$ ) for $\mathrm{FEV}_{1}$ and $\mathrm{FVC}$, and for the $\mathrm{FEV}_{1} / \mathrm{FVC}$ ratio an increase of $1 \%$ per doubling of the cumulative pollen count. Non-linearity was assessed by Generalized Additive Models (GAMs) ${ }^{16}$. Where non-linearity was detected, fractional polynomials were added to the linear regression to allow a flexible curve to be fitted to the dose-response data ${ }^{17}$. Figures were generated to describe the change in lung function related to change in early life pollen exposure, as fractional polynomials are difficult to interpret from a table. Natural cut-points

213 in the 3 month cumulative pollen data of 20,320 and 2950 grains $/ \mathrm{m}^{3}$ were used,

214 corresponding to the $10^{\text {th }}, 50^{\text {th }}$ and $75^{\text {th }}$ percentiles (Supplementary Figure 1). At both 12 and

21518 years we used pre-bronchodilator forced expiratory volume during the first second $216\left(\mathrm{FEV}_{1}\right)$, forced vital capacity $(\mathrm{FVC})$ and $\mathrm{FEV}_{1} / \mathrm{FVC}$ ratio in $\mathrm{mL}$. Bronchodilator response, $217>12 \%$ and $200 \mathrm{ml}$ increase from pre- to post- bronchodilator lung function ${ }^{18}$, was analyzed by 218 logistic regression at 18 years.

219

All regression models were adjusted a priori for age (years), height (cm), sex, maternal education and the presence of an URTI before 5 weeks. We dichotomized NDVI to assess effect modification, with "High residential greenness" defined as NDVI at birth in the $75^{\text {th }}$ percentile or greater. The level of $75^{\text {th }}$ percentile was selected a priori. We considered a $\mathrm{p}$ value $\leq 0.10$ as significant for the interaction terms and only present strata-specific results for significant interactions. Sensitivity analysis was conducted by removing all observations with imputed NDVIs without a cloud-free image. Interactions were also assessed at the $65^{\text {th }}$ and $70^{\text {th }}$ percentiles. We tested for effect modification by asthma diagnosis at $6 / 7$ years and sensitization to rye grass at 2 years.

Statistical analyses were performed using Stata release 14.1 (College Station, TX, USA).

\section{RESULTS}

234 Of the 620 original MACS participants, 486 (78\%) had lung function measurements at age 12 or age 18 years. Grass pollen data were available for 320 of these $(66 \%)$. There was no significant difference between the groups of participants with or without grass pollen data in terms of sex, URTI before 5 weeks, early sensitization or childhood asthma (Table 1). Those 
with pollen data are significantly younger as pollen data were not available at the start of recruitment.

\section{The association between exposure to grass pollen and lung function outcomes}

Cumulative grass pollen exposure over the first seven days of life varied from zero to 1878 grains $/ \mathrm{m}^{3}$ with a median of 17 grains $/ \mathrm{m}^{3}$. Exposure over the first three months was similarly varied (median: 320 grains $/ \mathrm{m}^{3}$, range: $7-7349$ ).

\section{Cumulative grass pollen exposure over the first seven days was associated with a} significantly reduced FVC ( $\beta$ : $-20.8 \mathrm{~mL} 95 \% \mathrm{CI}$ : $-35.4,-6.1$ per doubling of pollen count) and $\mathrm{FEV}_{1}(\beta:-15.5 \mathrm{~mL} 95 \% \mathrm{CI}:-27.6,-3.3)$ at age 12 in adjusted models (Table 2). Cumulative grass pollen exposure over the first three months of life revealed no association with $\mathrm{FEV}_{1}$ or $\mathrm{FVC}$, however it was associated with a small increase in the $\mathrm{FEV}_{1} / \mathrm{FVC}$ ratio at age 18 years ( $\beta: 0.4 \%$ 95\%CI: $0.1,0.7)$.

Unlike the first seven days, cumulative grass pollen exposure over the first three months of life showed a non-linear association with lung function (Figure S2). Comparing cut-points of the three month pollen data to the reference category of $0-19$ grains $/ \mathrm{m}^{3}$ of grass pollen showed a significant, but non-linear reduction in $\mathrm{FEV}_{1}$ and $\mathrm{FVC}$ at 12 years (Table 2). All grass pollen measurements were associated with a slight increase in the $\mathrm{FEV}_{1} / \mathrm{FVC}$ ratio at age 18 years. Grass pollen was not associated with bronchodilator responsiveness at age 18 years (Table S1). The pattern of associations is consistent when GLI z-scores are used (Table $\mathrm{S} 2)$.

\section{Effect modification by satellite measures of residential greenness}

The association between cumulative pollen exposure in the first three months of life and lung function in the high NDVI strata is clearly non-linear ( $p$-values $<0.01$; Figure 1). The pattern is similar for both $\mathrm{FEV}_{1}$ and $\mathrm{FVC}$ at both time points. The initial drop and then levelling out seen here can also be seen in the associations with the cut-off values in Tables S3 and S4. Sensitivity analysis (Table S5) showed no major differences in the effect sizes. The result was robust to changes in the definition of high NDVI from $75^{\text {th }}$ percentile to $70^{\text {th }}$ percentile (Table S6). However, the reference category of 0 -19 grains $/ \mathrm{m}^{3}$ of pollen represents a small number of children with good lung function (Table S7). Altering the reference category to the larger and more stable segment of the population represented by $20-320$ grains $/ \mathrm{m}^{3}$ of cumulative pollen exposure in the first three 
months of life (Table S8 and Table S9), reveals a significant interaction $(p<0.01)$ in the low pollen group.

Neither childhood asthma nor early sensitization to rye grass pollen modified the association between cumulative grass pollen exposures and lung function (data not shown).

\section{DISCUSSION}

Our study is the first to show an association between exposure to ambient grass pollen in the first 3 months of life and lung function later in childhood and adolescence. The association was evident at 12 years of age, with cumulative grass pollen exposure over the first seven days of life associated with significant reductions in $\mathrm{FEV}_{1}$ and FVC. Higher pollen counts over the first 3 months of life were associated with a reduction in FVC at 12 and 18 years. Exposure to ambient grass pollen in the first seven days and 3 months of life was also associated with a slight increase in the $\mathrm{FEV}_{1} / \mathrm{FVC}$ ratio at age 18 , due to reduction in $\mathrm{FVC}$ but preserved $\mathrm{FEV}_{1}$.

This study adds to a growing body of literature that suggests pollen exposure in early life is an important early life risk factor for allergic respiratory diseases later in childhood and adolescence. However, most studies showing such associations have only used month or season of birth as a surrogate measure of pollen exposure ${ }^{19-28}$, with fewer studies using actual ambient pollen counts ${ }^{9,10,29}$.

Exposure to pollen in early life is but one of several factors potentially contributing to the complex set of determinants of an individual's lung function throughout life ${ }^{30}$. Several of these factors temporally coincide with the cyclic nature of the pollen seasons. Early life respiratory tract infections ${ }^{31}$ and low maternal vitamin D levels ${ }^{32}$ also exhibit strong seasonal variation and have been associated with lung function in childhood and adolescence. Residual confounding by other seasonal effects complicate the interpretation of findings of studies using season of birth, and this may explain why some studies concluded that birth during the pollen season was associated with a decreased risk of atopic diseases ${ }^{19,26,27}$ rather than an increase $20-22,24,28$.

We have attempted to mitigate the effect of residual confounding by using actual pollen exposure rather than season and included URTI within 5 weeks after birth as a proxy for the 
rates of circulating respiratory viruses in early life. Neither of these altered the associations with pollen. Data was not available on maternal vitamin D levels so residual confounding may remain.

Studies using ambient pollen concentrations have shown that exposure was associated with increased odds of wheeze at 2 years of age ${ }^{10}$, asthma and allergic rhinitis at $6 / 7$ years of age ${ }^{9}$, and hospitalization for asthma within the first year of life ${ }^{29}$. However even here, there is debate as to whether it is pollen exposure in late pregnancy or early life that is more important.

While the changes to lung function associated with early life exposure to grass pollen that we observed in this study were relatively small compared to the effects of early tobacco smoke exposure ${ }^{33}$, they were similar to the effect sizes seen with exposure to traffic-related air pollution during the first year of life ${ }^{34}$. Changes in adolescent lung function carry life longterm implications for lung development and overall respiratory morbidity.

Satellite measures of residential greenness can be used to identify point sources of pollen not detected by a central monitor ${ }^{35}$. A central trap only collects data on wind borne pollen which may have travelled large distances, depending on wind direction, speed and local topography. Combining the ambient pollen count from the trap and the satellite measures of residential greenness surrounding the participants' home may more accurately reflect pollen exposure. When satellite measures of residential greenness at birth were considered as an effect modifier, NDVI modified the associations between cumulative grass pollen exposure at 3 months and $\mathrm{FEV}_{1}$ and $\mathrm{FVC}$ at both 12 and 18 years. In children with high greenness exposures (NDVI $>75 \%$ le), low exposure to pollen (0-19 grains) in the first three months of life was associated with increased $\mathrm{FEV}_{1}$ and FVC. Greenness has been shown to have both positive and negative effects on atopic respiratory diseases ${ }^{12}$, and the underlying biological mechanisms are not yet clear ${ }^{36}$. Point source pollination and the natural filtering of far travelling pollen of residential green space could be contributing factors. The amount of greenness may also impact on the more direct exposure to pollens in terms of behavior ${ }^{37}$ with access to parks and increased walkability positively correlated to greenness and time spent outside ${ }^{38}$.

\section{Strengths and Limitations}

This article is protected by copyright. All rights reserved 
340 A major strength of our study was the access to daily counts of grass pollen collected through

341 the year. Although this was not available for the entire MACS cohort, we were able to use

342 actual counts in the majority, permitting accurate assessment of any effect due to grass

343 pollen. While there is still potential for residual confounding by a range of factors that

344 temporally coincide with high pollen exposure, effects seen in proxy measures such as birth

345 during the pollen season or month of birth are more susceptible to such. However, only one

346 centrally located Burkard trap was available to collect daily levels of pollen, which will have

347 resulted in some misclassification of the actual pollen exposure for individual children due to

348 spatial variability. However, we focused on grass pollen as the prominent allergenic species

349 in this region and the majority of pollen comes from distant grasslands and is distributed over

350 the city of Melbourne ${ }^{9}$. As such, during peak grass pollen seasons, all individuals are likely

351 to receive similar exposures.

353 We had to impute NDVI values for approximately $5 \%$ of our sample with pollen data. The sensitivity analysis removing these observations also showed similar associations.

355 Nevertheless, missing NDVI data are a potential limitation of our analysis. A further

356 limitation arises from the presentation of the pre-bronchodilation lung function results.

357 Presumably, the deficit in $\mathrm{FEV}_{1}$ at 12 years is related to active asthma causing obstruction,

358 but we cannot be sure of this, as we did not administer a bronchodilator. By 18 years, there

359 has been dramatic expansion of the airways, and also a decline in the prevalence of asthma.

360 As such, it is less likely for an impairment to be detectable. It is also possible that as

361 participants age, the influence of early life factors is likely to wane.

362

363 Conclusion

364 Grass pollen exposure in the first months of life is associated with lower lung function later in childhood and adolescence. In children with high greenness exposures, low pollen exposure in the first three months of life was associated with increased $\mathrm{FEV}_{1}$ and FVC. This effect is possibly capturing behavioral differences in the way local populations interact with their environments which is likely to be related to the degree of greenness. Further research is needed to replicate these findings in a larger cohort of children with varying family history of allergic disease and deepen understanding of the mechanisms by which early life pollen exposure could affect lung function. Exposure to grass pollen at critical time periods during early life may be associated with some form of structural change in the lung parenchyma. If replicable, these findings would support the development of targeted interventions for pollen 
374

375

376

377

378

379

380

381

382

383

384

385

386

387

388

389

390

391

392

393

394

395

396

397

398

399

400

401

avoidance strategies that take into account local topography that could be implemented alongside other clinical interventions such as immunotherapy.

\section{ACKNOWLEDGEMENTS}

We wish to acknowledge the late Bruce Knox who set up and organized the pollen collector from which we drew the historical pollen counts used in this analysis.

\section{REFERENCES}

1. Soriano JB, Abajobir AA, Abate KH, et al. Global, regional, and national deaths, prevalence, disability-adjusted life years, and years lived with disability for chronic obstructive pulmonary disease and asthma, 1990-2015: a systematic analysis for the Global Burden of Disease Study 2015. The Lancet Respiratory Medicine. 2017;5(9):691-706.

2. Bui DS, Burgess JA, Lowe AJ, et al. Childhood Lung Function Predicts Adult Chronic Obstructive Pulmonary Disease and Asthma-Chronic Obstructive Pulmonary Disease Overlap Syndrome. American Journal of Respiratory and Critical Care Medicine. 2017;196(1):39-46.

3. Gehring U, Gruzieva O, Agius RM, et al. Air pollution exposure and lung function in children: The ESCAPE project. Environ Health Perspect. 2013;121(11-12):13571364.

4. Götschi T, Heinrich J, Sunyer J, Künzli N. Long-Term Effects of Ambient Air Pollution on Lung Function: A Review. Epidemiology. 2008;19(5):690-701.

5. Baraldi E, Carra S, Dario C, et al. Effect of Natural Grass Pollen Exposure on Exhaled Nitric Oxide in Asthmatic Children. American Journal of Respiratory and Critical Care Medicine. 1999;159(1):262-266.

6. Roberts G, Hurley C, Bush A, Lack G. Longitudinal study of grass pollen exposure, symptoms, and exhaled nitric oxide in childhood seasonal allergic asthma. Thorax. 2004;59(9):752-756. 
$4027 . \quad$ Vahlkvist S, Sinding M, Skamstrup K, Bisgaard H. Daily home measurements of 403 exhaled nitric oxide in asthmatic children during natural birch pollen exposure. The $404 \quad J o u r n a l$ of Allergy and Clinical Immunology. 2006;117(6):1272-1276.

405 8. Gruzieva O, Pershagen G, Wickman M, et al. Exposure to grass pollen - but not birch 406 pollen - affects lung function in Swedish children. Allergy: European Journal of Allergy and Clinical Immunology. 2015.

9. Erbas B, Lowe AJ, Lodge CJ, et al. Persistent pollen exposure during infancy is 409 associated with increased risk of subsequent childhood asthma and hayfever. Clinical and Experimental Allergy. 2013;43(3):337-343.

10. Harley KG, Macher JM, Lipsett M, et al. Fungi and pollen exposure in the first months of life and risk of early childhood wheezing. Thorax. 2009;64(4):10.1136/thx.2007.090241.

11. Cilluffo G, Ferrante G, Fasola S, et al. Associations of greenness, greyness and air pollution exposure with children's health: a cross-sectional study in Southern Italy. Environmental Health. 2018;17(1):86.

12. Lambert K, Bowatte G, Tham R, et al. Greenspace and Atopic Sensitization in Children and Adolescents-A Systematic Review. Int J Environ Res Public Health. 2018;15(11):2539.

13. Lowe AJ, Lodge CJ, Allen KJ, et al. Cohort Profile: Melbourne Atopy Cohort study (MACS). International Journal of Epidemiology. 2017;46(1):25-26.

14. Lowe AJ, Hosking CS, Bennett CM, et al. Effect of a partially hydrolyzed whey infant formula at weaning on risk of allergic disease in high-risk children: a randomized controlled trial. J Allergy Clin Immunol. 2011;128(2):360-365 e364.

15. Lodge CJ,Lowe AJ, Allen KJ, et al. Childhood Wheeze Phenotypes Show Less Than Expected Growth in FEV1 across Adolescence. American Journal of Respiratory and Critical Care Medicine. 2014;189(11):1351-1358. 
428 16. Wood SN. Fast stable restricted maximum likelihood and marginal likelihood

429

430

431

432

433

434

435

436

437

438

439

440

441

442

443

444

445

446

447

448

449

450

451

452

453

454 estimation of semiparametric generalized linear models. Journal of the Royal Statistical Society: Series B. 2011;73(1):3-36.

17. Oddy WH, Sherriff JL, Klerk NHd, et al. The Relation of Breastfeeding and Body Mass Index to Asthma and Atopy in Children: A Prospective Cohort Study to Age 6 Years. Am J Public Health. 2004;94(9):1531-1537.

18. Pellegrino R, Viegi G, Brusasco V, et al. Interpretative strategies for lung function tests. Eur Respir J. 2005;26(5):948-968.

19. Chang W-C, Yang KD, Wu M-TM, et al. Close Correlation between Season of Birth and the Prevalence of Bronchial Asthma in a Taiwanese Population. PLoS ONE. 2013;8(11):e80285.

20. Gazala E, Ron-Feldman V, Alterman M, Kama S, Novack L. The association between birth season and future development of childhood asthma. Pediatric Pulmonology. 2006;41(12):1125-1128.

21. Graf N, Johansen P, Schindler C, et al. Analysis of the Relationship between Pollinosis and Date of Birth in Switzerland. International Archives of Allergy and Immunology. 2007;143(4):269-275.

22. Katebi R, Williams G, Bourke M, Harrison A, Verma A. What factors are associated with the prevalence of atopic symptoms amongst adolescents in Greater Manchester? European Journal of Public Health. 2015:ckv139-ckv139.

23. Kemp A, Ponsonby A-L, Dwyer T, et al. The interaction between early life upper respiratory tract infection and birth during the pollen season on rye-sensitized hay fever and ryegrass sensitization - a birth cohort study. Pediatric Allergy and Immunology. 2009;20(6):536-544.

24. Kihlström A, Lilja G, Pershagen G, Hedlin G. Exposure to high doses of birch pollen during pregnancy, and risk of sensitization and atopic disease in the child. Allergy. 2003;58(9):871-877. 
455

456

457

458

459

460

461

462

463

464

465

466

467

468

469

470

471

472

473

474

475

476

477

478

479

480

481

25. Knudsen TB, Thomsen SF, Ulrik CS, Fenger M, Nepper-Christensen S, Backer V. Season of Birth and Risk of Atopic Disease among Children and Adolescents. $J$ Asthma. 2007;44(4):257-260.

26. Lockett GA, Soto-Ramírez N, Ray MA, et al. Association of season of birth with DNA methylation and allergic disease. Allergy. 2016;71(9):1314-1324.

27. Nilsson L, Björkstén B, Hattevig G, Kjellman B, Sigurs N, Kjellman N-IM. Season of birth as predictor of atopic manifestations. Archives of Disease in Childhood. $1997 ; 76(4): 341-344$.

28. Pyrhönen K, Läärä E, Hiltunen L, Kaila M, Hugg T, Näyhä S. Season of the first trimester of pregnancy predicts sensitisation to food allergens in childhood: a population-based cohort study from Finland. Journal of Epidemiology and Community Health. 2012;66(1):49-56.

29. Lowe AJ, Olsson D, Braback L, Forsberg B. Pollen exposure in pregnancy and infancy and risk of asthma hospitalisation - a register based cohort study. Allergy, Asthma, \& Clinical Immunology: Official Journal of the Canadian Society of Allergy \& Clinical Immunology. 2012;8(1):17.

30. Luzak A, Fuertes E, Flexeder C, et al. Which early life events or current environmental and lifestyle factors influence lung function in adolescents? - results from the GINIplus \& LISAplus studies. Respiratory Research. 2017;18(1):138.

31. van Meel ER, den Dekker HT, Elbert NJ, et al. A population-based prospective cohort study examining the influence of early-life respiratory tract infections on school-age lung function and asthma. Thorax. 2018;73(2):167-173.

32. Zosky GR, Hart PH, Whitehouse AJO, et al. Vitamin D Deficiency at 16 to 20 Weeks' Gestation Is Associated with Impaired Lung Function and Asthma at 6 Years of Age. Annals of the American Thoracic Society. 2014;11(4):571-577.

33. Dai X, Dharmage SC, Lowe AJ, et al. Early smoke exposure is associated with asthma and lung function deficits in adolescents. J Asthma. 2017;54(6):662-669. 
482 34. Schultz ES, Hallberg J, Bellander T, et al. Early-life exposure to traffic-related air pollution and lung function in adolescence. Am J Respir Crit Care Med. 2016;193(2):171-177.

485

486

487

488

489

490

491

492

493

494

495

496

35. Skjøth CA, Ørby PV, Becker T, et al. Identifying urban sources as cause of elevated grass pollen concentrations using GIS and remote sensing. Biogeosciences. 2013;10(1):541-554.

36. Markevych I, Schoierer J, Hartig T, et al. Exploring pathways linking greenspace to health: Theoretical and methodological guidance. Environ Res. 2017;158(Supplement C):301-317.

37. World Health Organization. Urban green spaces and health. A review of evidence. Copenhagen: WHO Regional Office for Europe; 2016.

38. James P, Hart JE, Hipp JA, et al. GPS-Based Exposure to Greenness and Walkability and Accelerometry-Based Physical Activity. Cancer Epidemiology Biomarkers \&amp; Prevention. 2017;26(4):525-532.

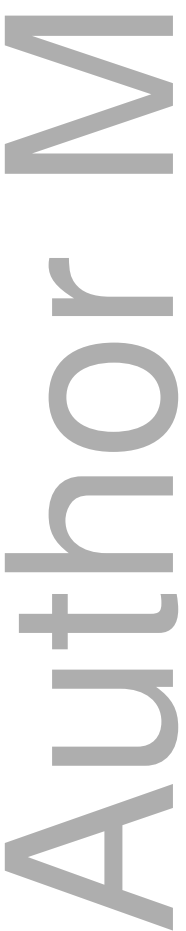


Table 1: Sample characteristics of the MACS participants with lung function data, with or without grass pollen data

498

\begin{tabular}{|c|c|c|c|}
\hline \multirow{2}{*}{ Childhood factors } & \multicolumn{2}{|c|}{ Pollen data available } & \multirow[b]{2}{*}{$\mathrm{p}$} \\
\hline & No $(\mathrm{N}=160)$ & Yes $(\mathrm{N}=326)$ & \\
\hline Male sex $\%(n)$ & $50(80)$ & $51(166)$ & 0.923 \\
\hline URTI before 5 weeks & $5(8)$ & $2.8(9)$ & 0.292 \\
\hline Sensitisation 2 yrs & $11(17)$ & $6.9(22)$ & 0.152 \\
\hline Childhood asthma & $45(64)$ & $40(122)$ & 0.305 \\
\hline \multicolumn{4}{|l|}{ Age (in years) } \\
\hline Age 12 & $12.75 \pm 1.65$ & $10.94 \pm 1.66^{*}$ & $<0.001$ \\
\hline Age 18 & $19.14 \pm 1.02$ & $17.41 \pm 1.07^{*}$ & $<0.001$ \\
\hline \multicolumn{4}{|l|}{ Lung Function } \\
\hline Age 12 & $(n=115)$ & $(n=250)$ & \\
\hline $\mathrm{FEV}_{1}(\mathrm{~mL})$ & $2696 \pm 724$ & $2219 \pm 551 *$ & $<0.001$ \\
\hline $\mathrm{FVC}(\mathrm{mL})$ & $2916 \pm 726$ & $2433 \pm 594^{*}$ & $<0.001$ \\
\hline $\mathrm{FEV}_{1} / \mathrm{FV}$ & $0.92 \pm 0.07$ & $0.91 \pm 0.07$ & 0.326 \\
\hline Age 18 & $(n=134)$ & $(n=275)$ & \\
\hline $\mathrm{FEV}_{1}(\mathrm{~mL})$ & $3847 \pm 846$ & $3821 \pm 762$ & 0.769 \\
\hline $\mathrm{FVC}(\mathrm{mL})$ & $4594 \pm 1026$ & $4519 \pm 948$ & 0.478 \\
\hline $\mathrm{FEV}_{1} / \mathrm{FVC}$ & $0.84 \pm 0.08$ & $0.85 \pm 0.07$ & 0.307 \\
\hline
\end{tabular}

499 Data presented as $\%$ and (number) or mean \pm SD.

$500 * \mathrm{*}<0.05$

This article is protected by copyright. All rights reserved 
Table 2: The association between grass pollen exposure and lung function measures

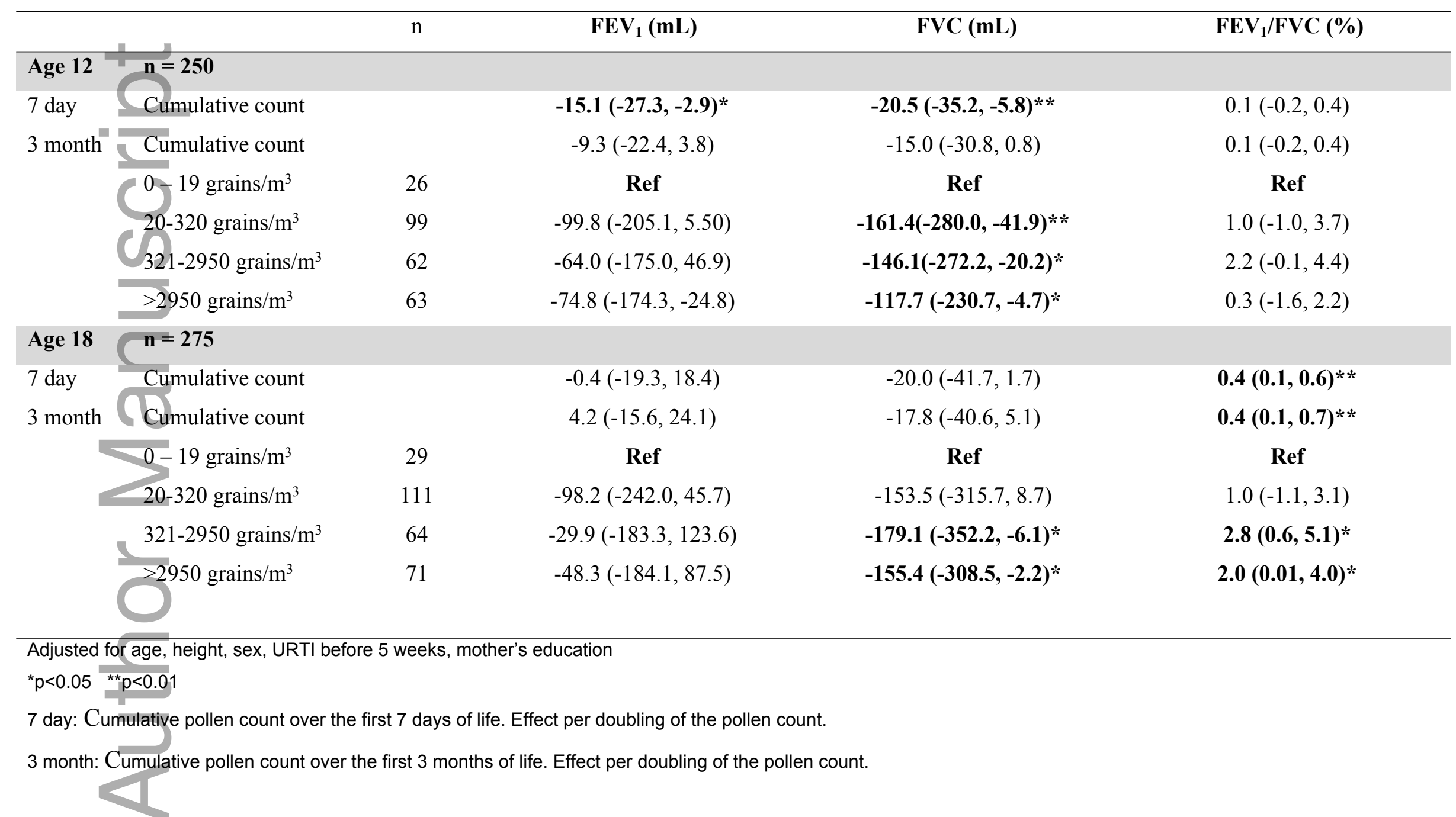

This article is protected by copyright. All rights reserved 
Pollen exposure at birth and adolescent lung function, and modification by residential greenness

Katrina A Lambert, Caroline Lodge, Adrian J Lowe, Luke A Prendergast, Paul S Thomas, Catherine M Bennett, Michael J Abramson, Shyamali C Dharmage, Bircan Erbas

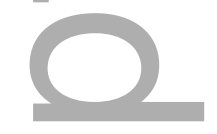

- Early life exposure to pollen was associated with reduced lung function at 12 years in a high-risk birth cohort.

- Associations with a non-linear reduction in forced vital capacity (FVC) were also apparent at 18 years.

- Exposure to high residential greenness modified the association at 18 years.

$\mathrm{FEV}_{1}$ : Forced expiratory volume during the first second; FVC: forced vital capacity

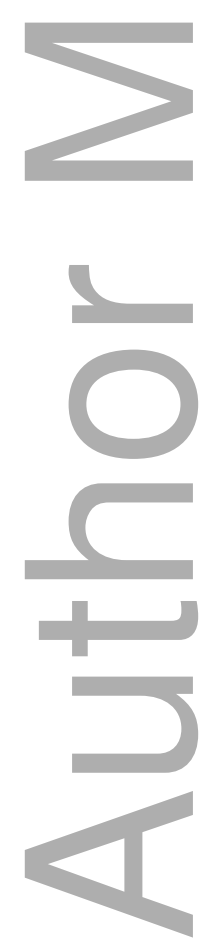


all_13803_f1.pdf
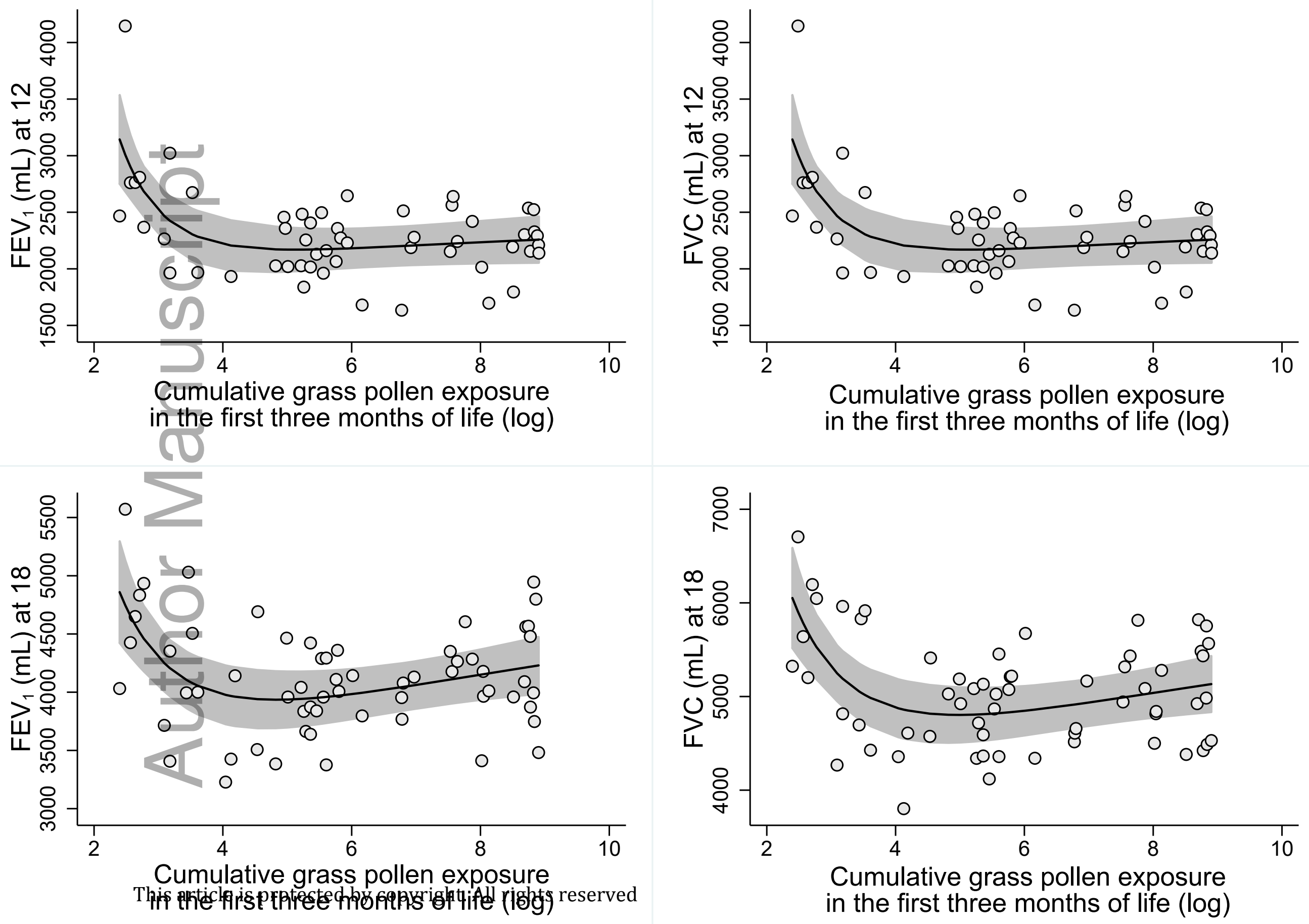


\section{University Library}

\section{- M M N E R VA A gateway to Melbourne's research publications}

Minerva Access is the Institutional Repository of The University of Melbourne

\section{Author/s:}

Lambert, KA;Lodge, C;Lowe, AJ;Prendergast, LA;Thomas, PS;Bennett, CM;Abramson, $\mathrm{MJ}$;Dharmage, SC;Erbas, B

Title:

Pollen exposure at birth and adolescent lung function, and modification by residential greenness

Date:

2019-10-01

Citation:

Lambert, K. A., Lodge, C., Lowe, A. J., Prendergast, L. A., Thomas, P. S., Bennett, C. M., Abramson, M. J., Dharmage, S. C. \& Erbas, B. (2019). Pollen exposure at birth and adolescent lung function, and modification by residential greenness. ALLERGY, 74 (10), pp.1977-1984. https://doi.org/10.1111/all.13803.

Persistent Link:

http://hdl.handle.net/11343/285737 